\title{
DEJAR DE INFORMAR: LA PRENSA ITALIANA Y EL DEBATE SOBRE EL «APAGÓN INFORMATIVO» TRAS LOS ATAQUES DE LAS BRIGADAS ROJAS
}

\section{REPORTING CEASED: THE ITALIAN PRESS AND THE DEBATE CONCERNING THE MEDIA BLACKOUT AFTER THE RED BRIGADES ATTACKS}

\author{
Matteo Re \\ Universidad Rey Juan Carlos, España \\ Orcid.org/0000-0002-1782-3746
}

Recibido el 1-2-2017 y aceptado el 1-6-2017

Resumen: Este trabajo analiza la actitud de la prensa frente a la amenaza terrorista de las Brigadas Rojas y la oportunidad de limitar la información relacionada con la banda. El grupo terrorista de las Brigadas Rojas después de cada atentado solía difundir unos comunicados de reivindicación de sus acciones violentas. Con el paso del tiempo, ese goteo de información suministrada por parte de los terroristas hizo que el mundo del periodismo cuestionara la oportunidad de seguir publicando los textos que provenían de una banda armada. El debate se hizo particularmente intenso durante dos acciones perpetradas por los brigadistas: los secuestros, por un lado del presidente de la Democracia Cristiana Aldo Moro, que acabaría con la muerte del rehén, y por otro, del juez Giovanni D’Urso, liberado tras más de un mes de cautiverio.

Palabras clave: Italia, Brigadas Rojas, Terrorismo, Prensa, Lenguaje.

\footnotetext{
Abstract: This paper carries out an analysis of the attitude of the press regarding the Red Brigades terrorist threat and the subsequent opportunity to restrict flow of information concerning the group. The terrorist group the Red Brigades used to claim responsibility for their violent actions after each attack. Over time, that information coming from a terrorist group made mass media question the morality of continuing to publish texts written by terrorists. The discussion was extremely heated on two occasions, when the Red Brigades kid-
} 
napped, on one hand, the Christian Democracy President, Aldo Moro, who was killed, and on the other hand, judge Giovanni D'Urso, who was released one month later.

Keywords: Italy, Red Brigades, Terrorism, Press, Language. 


\section{Introducción}

Según André Glucksmann, «un atentado no tiene éxito si no se queda grabado en el cerebro de los supervivientes» ${ }^{1}$. Una de las maneras para que un ataque terrorista persista en la memoria, y que incluso pueda convertirse en algo aún más terrible de lo que realmente fue, es que tenga una elevada repercusión mediática. Desde el punto de vista de un terrorista, aquella acción armada que, a pesar de matar a un gran número de personas, no logre una amplia difusión, será un fracaso. Ramdane Abane, uno de los líderes del Frente de Liberación Nacional de Argelia, afirmaba que entre matar a diez enemigos en un remoto valle donde nadie hablaría de ello o uno solo en el centro de Argel, la segunda opción era sin duda preferible ya que tendría una repercusión infinitamente mayor. De hecho, tal y como destaca Pedro Rivas Nieto, a menudo desde la óptica de una organización terrorista «el éxito militar es secundario, lo importante es el éxito informativo» ${ }^{2}$. Se podría llegar así a validar las teorías de Marshall McLuhan y Jean Baudrillard que, de manera evidentemente provocativa, afirmaban que «sin medios de comunicación no habría terrorismo» ${ }^{3}$.

Sin llegar a estos extremos, algo impensable en una sociedad abierta, plural y moderna, en Italia sí que se planteó modificar la manera de informar sobre el terrorismo. La cuestión planteada por parte de intelectuales y periodistas, y que dio pie a unos interesantes - aunque poco efectivos - debates, se refería a la conveniencia de no convertir los medios de comunicación en caja de resonancia de la organización terrorista Brigadas Rojas. Se pretendía evitar que la difusión por parte de los periódicos de boletines, manifiestos, reivindicaciones de las BR y hasta de cartas redactadas por sus rehenes proporcionara una mayor visibilidad a su mensaje y acciones. En dos ocasiones concretas - los secuestros del presidente de la Democracia Cristiana Aldo Moro, primero, y del juez Giovanni D'Urso, después - se llegó hasta a plantear dejar de informar, llevar a cabo lo que se definió como «apagón informativo».

En realidad, el debate sobre la oportunidad de limitar la visibilidad otorgada a los terroristas se había producido ya con anterioridad al secuestro de Aldo Moro, si bien con este acto que tenía como víctima a uno de los políticos más destacados de Italia, la posibilidad de dejar de infor-

\footnotetext{
1 Glucksmann, 2005, p. 15.

2 Rivas Nieto, 2013, p. 119.

3 Ahora en Veres, 2004, p. 9.
} 
mar se convirtió, para algunos, casi en una necesidad o imperativo para preservar la integridad del país. En este artículo analizaremos la actitud de la prensa en relación a estos dos secuestros y el debate sobre la oportunidad de publicar las comunicaciones que enviaban los brigadistas. Para ello, estudiaremos algunos artículos publicados por los periódicos de mayor difusión de la época, como eran el Corriere della Sera, L'Unità, La Repubblica, Il Giornale, pero también otros de menor alcance que, sin embargo, se sumaron a ese debate, ya que toda la prensa italiana se vio involucrada en la necesidad de dar una respuesta a lo que se convirtió en un verdadero chantaje por parte de las Brigadas Rojas.

El objetivo de esta investigación es ver qué consecuencias tuvieron las confrontaciones entre los planteamientos promovidos por las direcciones de los diferentes periódicos italianos: si hubo uniformidad, cohesión a nivel periodístico o si ese debate abrió brechas entre los diferentes rotativos. Nos centraremos también en la propuesta de «informar con reservas» durante los secuestros de Aldo Moro y de Giovanni D’Urso.

\section{Periodismo en evolución}

Debido a que en este artículo se citarán muchos periódicos de diferente orientación política y de distinta pertenencia editorial, nos parece fundamental, para facilitar la lectura, dedicar un breve apartado a la situación del periodismo italiano en los años analizados en este trabajo.

Los años setenta, en Italia, fueron un periodo de efervescencia cultural y no solo años de violencia política, como se les suele recordar, de manera demasiado apresurada. A partir del bienio 1968-1969 aparecieron nuevos periódicos para dar voz a los contestatarios que se aunaban en las organizaciones de extrema izquierda o en el movimiento estudiantil. Il Manifesto fue quizá el más representativo de ellos. Fundado en 1969 por unos tránsfugas del Partido Comunista Italiano descontentos con la actitud del partido considerada demasiado reformista y poco revolucionaria, empezó su andadura como revista mensual, pero, a partir de 1971, pasó a venderse a diario. Hasta 1974 fue el órgano de prensa de un partido homónimo, que a partir de esa fecha confluyó en la coalición Partito di Unità Proletaria per il Comunismo (PdUP) que a su vez desapareció en 1984. Lotta Continua fue otro periódico que sobrevivió a la organización de extrema izquierda que le dio el nombre y que, una vez convertida en partido político, fracasó rotundamente en su carrera parlamentaria desapareciendo en poco 
tiempo. El diario fue fundado en 1969, pero solo en 1972 pasó a venderse con edición diaria. Era un rotativo caracterizado por sus artículos agresivos y sus titulares impactantes, especialmente apreciados por los jóvenes contestatarios de la Nueva Izquierda italiana.

El Corriere della Sera es el periódico con mayor distribución en Italia. Es también uno de los más antiguos, ya que fue fundado en 1876 en Milán. Justamente durante los años setenta, el periódico vivió unos años convulsos reflejados en la sucesión de tres directores en poco más de una década: Giovanni Spadolini (1968-1972), Piero Ottone (1972-1977) y Franco Di Bella (1977-1981). Bajo la dirección de Giovanni Spadolini (quien se convertiría en líder del Partido Republicano en 1979 y presidente del Consejo de Ministros entre 1981 y 1982) la orientación del periódico fue favorable a la unión de los partidos de centro con la izquierda reformista, planteamiento que excluía el Partido Comunista Italiano de un posible gobierno. Su sucesor, Piero Ottone, predicó un estilo periodístico alejado de conformismos y prejuicios. Valga como ejemplo de ese planteamiento el título de uno de sus artículos sobre la libertad de prensa: «No esconder nada». Desde un punto de vista político, la presidencia de Ottone se caracterizó por un paulatino, aunque moderado, alejamiento del partido de gobierno, la Democracia Cristiana, y una suavización hacia el Partido Comunista Italiano. Ese giro no gustó a muchos de los lectores, en su mayoría pertenecientes a la burguesía tradicional. Entre los propios periodistas algunos exteriorizaron con determinación su rechazo a la nueva orientación del periódico. Uno de ellos, Indro Montanelli, fue despedido en 1973 y, un año más tarde, creó Il Giornale (que durante un tiempo se llamó Il Giornale Nuovo), un diario que se oponía al nuevo planteamiento del Corriere della Sera abrazando una línea política moderada, más tradicional y crítica hacia la izquierda italiana. Volviendo al Corriere della Sera, el tercer director en menos de diez años fue Franco Di Bella. Su llegada se debió a una oscura operación de recapitalización del periódico en grave crisis económica. La nueva línea política suavizó sus divergencias con el gobierno y abandonó el acercamiento a las posiciones más progresistas. Cuando, en el mes de abril de 1981, se supo que entre los afiliados a la logia masónica Propaganda 2 (P2) se encontraban hasta veintiocho periodistas, siete altos directivos y el editor Angelo Rizzoli, todos ellos del Corriere della Sera, el escándalo fue enorme, tanto es así que Di Bella dejó la dirección del periódico.

Unos años antes, en 1976, había nacido otro periódico que se convertiría en un rotativo de referencia en el periodismo italiano. La Repubblica 
orientó su línea editorial de manera clara tal y como escribió su director, Eugenio Scalfari, en una nota de presentación al primer número: «este periódico [...] está hecho por hombres que pertenecen al vasto abanico de la izquierda italiana $»^{4}$. La Repubblica era «hija» de la revista L'Espresso, que el mismo Scalfari había fundado en 1955. De hecho, al principio, se llegó a decir que la diferencia entre ambos rotativos era la frecuencia de publicación, uno salía a la venta todos los días el otro una vez al mes.

Los demás periódicos analizados en este trabajo son de carácter regional o local. Il Tempo de Roma, Il Messaggero de Roma, Il secolo XIX de Génova, Il Lavoro de Génova (perteneciente al mismo grupo editorial que el Corriere della Sera), Il Resto del Carlino de Bolonia, La Nazione de Florencia, Il Giorno de Milán. Estos tres últimos pertenecían al mismo grupo editorial, aunque la actitud de sus directores en los casos analizados no siempre fue unitaria. Il Giorno en los años sesenta era el cuarto diario más vendido de Italia. Sin embargo, con el nacimiento de La Repubblica, cuya orientación política era casi idéntica, perdió a muchos corresponsales y a lectores.

Al margen de los periódicos privados están los periódicos de partido. En este artículo solo se citan dos: L'Unità y L'Avanti! órganos de prensa respectivamente del Partido Comunista Italiano y del Partido Socialista Italiano.

\section{Plantearse no informar}

El 16 de marzo de 1978 las Brigadas Rojas secuestraron al presidente de la Democracia Cristiana, Aldo Moro, y mataron a los cinco agentes que lo escoltaban.

Ese secuestro, que duró 55 días, tras los cuales los terroristas asesinaron al rehén, encendió un intenso debate político sobre qué hacer, cómo reaccionar a ese acto extremo y tan descomunal que unos militantes de una organización clandestina habían llevado a cabo sin que las Fuerzas de Seguridad del Estado lograran detenerlo. La posición del partido de gobierno, la Democracia Cristiana, se mantuvo firme en contra de cualquier tipo de pacto con los brigadistas. Esa postura, tras la muerte de Moro, recibió muchas críticas ya que propiciaba un sentimiento de abandono hacia

${ }^{4}$ Murialdi, 1986, p. 222. 
el compañero de partido, actitud que - se decía - Moro nunca hubiera permitido para ninguno de sus colegas. Famoso es, de hecho, el discurso que el estadista democristiano dio a los grupos parlamentarios el 28 de febrero de 1978 (unas dos semanas antes del secuestro), que concluía con estas emotivas palabras: «tenemos que andar juntos, porque el futuro nos pertenece, en larga medida, también a nosotros» ${ }^{5}$.

El Partido Comunista Italiano adoptó una posición, si cabe, aún más intransigente que la gubernamental, caracterizada por un cierre total a cualquier tipo de dialogo con los terroristas. En general, los demás partidos se mantuvieron firmes en el rechazo hacia los brigadistas, posición que no se modificó durante toda la duración del secuestro. Los únicos partidos políticos que se plantearon abrir unas negociaciones directas con las Brigadas Rojas, como recurso último y desesperado para salvar la vida del estadista, fueron los grupos de la izquierda extraparlamentaria, el Partido Radical Italiano y, sobre todo, el Partido Socialista Italiano, dirigido por el nuevo secretario Bettino Craxi orientado al alejamiento del Partido Comunista Italiano.

Tras esta breve introducción sobre el debate político acontecido durante los días del secuestro, pasamos a analizar la prensa. El Corriere della Sera, en su editorial del 17 de marzo de 1978, declaraba que los terroristas «a través del secuestro de Aldo Moro demostraron una capacidad de atacar superior a la que habían acostumbrado con anterioridad» ${ }^{6}$. La prensa italiana, ante la brutalidad del acto cometido, presentó una imagen de fortaleza de los terroristas.

Sin embargo, al margen de la infinidad de artículos publicados a diario exaltando la fuerza militar de las Brigadas Rojas, hubo quien, como Umberto Eco, propuso, en una reflexión publicada en la revista L'Espresso unos días más tarde, «hablar lo menos posible» de lo ocurrido ya que ese tipo de ataque había sido llevado a cabo con la intención manifiesta de que la prensa hablara de ello ${ }^{7}$. Las palabras de Eco entroncaban con unas declaraciones que el filósofo canadiense Marshall McLuhan había hecho en una entrevista al periódico Il Tempo el 19 de febrero de ese

5 Ahora en www.apolis.com/Moro.

6 «Reagire con forza», Corriere della Sera, 17-III-1978.

7 Umberto Eco, «Il silenzio è di piombo», L'Espresso, 2-IV-1978, pp. 13-15. Esa misma idea había aparecido en las páginas de L'Espresso el 5 de marzo, diez días antes del secuestro de Aldo Moro. Sobre las declaraciones de Umberto Eco véase también Bechelloni, 1978, pp.171-178. 
mismo año, es decir antes de que se produjera el secuestro de Aldo Moro. Su exhortación a «desenchufar la información» (staccare la spina) hacía hincapié en la necesidad de no alentar al terrorismo y, si fuera necesario, ignorarlo por completo ${ }^{8}$. El mensaje de McLuhan y Eco era claro: para derrotar a los terroristas no era suficiente perseguirles policialmente, hacía falta quitarles esa caja de resonancia que los medios de comunicación, aunque de manera involuntaria, les brindaban.

Hubo quien, como el poeta Eugenio Montale, sugirió no publicar «todo lo que provenía de la prisión del pueblo» ${ }^{9}$. Sin embargo, según Lamberto Pignotti, de L'Unità, sí que era necesario publicar los documentos de las Brigadas Rojas, pero hacía falta hacerlo «sin excederse en la magnificación ni permitir el sensacionalismo». El periodista hacía también referencia explícita a la foto que los brigadistas difundieron junto con su primer mensaje y en la que aparecía Aldo Moro con una camisa arrugada, con cara demacrada y a sus espaldas, desplegada contra la pared, la bandera de la organización que lo había secuestrado. El hecho en sí de difundir esa imagen no era, siempre según la opinión de Pignotti, algo censurable, siempre y cuando no se sobrepasase la frontera que separa la crónica informativa y el sensacionalismo ${ }^{10}$. Giampaolo Pansa, periodista de La Repubblica, casi parafraseando el pensamiento del partido del gobierno, pedía a sus colegas de profesión que no dejaran de publicar el material entregado por los terroristas, pero que lo hicieran con responsabilidad ${ }^{11}$. El director de ese mismo periódico, el 22 de marzo, escribía un artículo en el que se preguntaba, y de paso extendía esa cuestión al resto de los periodistas, si lo que estaba en juego era la seriedad periodística de publicar una noticia contrastada o si, por otra parte, había que evitar publicar noticias indeseables, inquietantes, que pudieran crear divisiones y aumentar el pánico entre la gente ${ }^{12}$. En este segundo caso, el director decía que no era posible dejar de informar, ya que siempre primaba la necesidad de difundir noticias, con la exigencia, claro está, de que fueran contrastadas.

8 Gino Fantauzzi, «Intervista a McLuhan», Il Tempo, 19-II-1978.

9 «Un caso di coscienza. Pubblicare o no i documenti dei terrorista?», Corriere della Sera, 21-III-1978.

${ }^{10}$ Lamberto Pignotti, «Il terrorista in prima pagina», L'Unità, 25-III-1978.

11 Giampaolo Pansa, «Silenzio stampa sul «processo» a Moro? La DC chiede cautela a giornali e RAI», La Repubblica, 21-III-1978.

12 Eugenio Scalfari, «Il caso di coscienza che turba i giornalisti», La Repubblica, 22III-1978. 
En otro artículo de ese mismo día, también La Repubblica publicaba una entrevista a once directores de periódicos nacionales. En realidad se les pedía que contestaran a tan solo una pregunta: «Si os llegara una confesión de Aldo Moro, sacada a un hombre que carece de sus plenas facultades, pero de la que se pueda contrastar su autenticidad (por la voz o por la grafía), una confesión en la que, por ejemplo, se afirma que la Democracia Cristiana y el Gobierno jugaron un papel protagonista en la estrategia de tensión, ¿cuál sería vuestra conducta? ¿publicaríais dicha confesión o no?». Estas fueron las respuestas: Alberto Sensini, de La Nazione, contestó que no, que no la publicaría al tratarse de una confesión obtenida por la fuerza y la intimidación; Michele Tito, de Il secolo XIX, Luigi Fossati, de Il Messaggero, Gaetano Afeltra, de Il Giorno e Indro Montanelli, de Il Giornale, tenían una opinión diferente a la de su compañero. Ellos sí hubieran publicado ese texto, especificando que muy probablemente era fruto de la extorsión y no de una libre reflexión, lo cual lo convertía en un documento sin valor. El director de Il Tempo, Gianni Letta - el periódico que un mes antes había publicado la entrevista a McLuhan - tras unos titubeos iniciales, acabó conviniendo que no hubiera publicado el texto; lo mismo habría hecho Arrigo Levi, de La Stampa. Tampoco Aniello Coppola, de Paese Sera, habría cedido al chantaje de los terroristas, aunque se preguntaba si la autocensura hubiera servido de algo para progresar en la investigación. Tino Neirotti, director de Il Resto del Carlino, habría publicado por dos razones: porque callar habría sido como afirmar que las Brigadas Rojas habían ganado, y también porque su convicción era que la inmensa mayoría de los italianos habrían apoyado al Estado y a Aldo Moro y nunca a los terroristas. Ennio Caretto, de La Stampa, no sabía qué contestar, no tenía una idea clara debido a que la situación era del todo inusual. Por último, el director de Il Corriere della Sera, Franco Di Bella, se habría fijado primero en la reacción de los demás compañeros de profesión y, de manera conjunta, habría decidido si publicar o no esa información. Al tratarse de un problema global, según Di Bella, hacía falta una respuesta unánime y no aislada ${ }^{13}$. Sin embargo, tal y como se puede observar, esa uniformidad revindicada por parte del director del primer periódico italiano no existía. Cada uno planteaba una respuesta diferente, heterogé-

${ }^{13}$ Giampaolo Pansa, «E quando in redazione arriverà il nastro con la voce di Moro?», La Repubblica, 22-III-1978. 
nea, en la que predominaban confusión, falta de cohesión, incertidumbre y estupor.

El 26 de marzo, el profesor Marino Livolsi, decano de la facultad de Sociología de la Universidad de Trento, el mismo centro en el que estudiaron algunos de los fundadores de las Brigadas Rojas, entrevistado por el Corriere della Sera, declaró que las Brigadas Rojas no tenían secuestrado solo a Aldo Moro, sino también a los medios de comunicación italianos, detectando el riesgo de que «periódicos y televisión se ajustaran a los dictámenes impuestos por los terroristas» ${ }^{14}$. Y así fue, porque a pesar de las opiniones divergentes sobra la oportunidad de publicar una posible declaración de Aldo Moro, cuando esta llegó, todos acabaron divulgándola, imprimiendo además una notable carga sensacionalista a todo lo que salía de la prisión de las Brigadas Rojas ${ }^{15}$.

\section{Cartas, comunicados y artículos}

Cuando las Brigadas Rojas, en su afán de llevar la voz cantante en todo momento, y probablemente infravalorando las consecuencias que dicha estrategia conllevaría, comenzaron a difundir, junto con sus comunicados de reivindicación, las cartas que el político estaba redactando desde su cautiverio, la prensa reaccionó desacreditando al rehén.

Eso empezó incluso antes de que Aldo Moro escribiera su primera misiva. El 19 de marzo, casi de manera preventiva, Il Giornale advertía de la necesidad de «acoger con reticencias cualquier confesión proveniente de Aldo Moro», alegando la posibilidad de que los terroristas le drogaran y le forzaran a escribir lo que ellos querían ${ }^{16}$. Unos diez días más tarde, el 29 de marzo, llegó a los periódicos la primera misiva redactada por el estadista. Iba dirigida al ministro del Interior, Francesco Cossiga, y en ella Moro hablaba de la posibilidad por parte del Gobierno (o sería mejor decir deseo/necesidad) de llegar a un acuerdo con los terroristas ${ }^{17}$. En reali-

14 Giancarlo Pertegato, «Le BR hanno in ostaggio non soltanto Moro, ma anche i nostri mezzi di comunicazione», Corriere della Sera, 26-III-1978.

15 Véanse, por ejemplo, Grossi, 1981, pp. 68-69.

16 Indro Montanelli, «In che mani», Il Giornale, 19-III-1978.

${ }^{17}$ El secuestrado, en adelante, se convertiría en el principal acusador de sus compañeros políticos, destapando, carta tras carta, las incongruencias internas presentes en su partido, los antagonismos las divisiones, las trifulcas. Los brigadistas, con sus comunicados, 
dad, no quedaba claro sobre qué había de versar el pretendido acuerdo, ya que los brigadistas no habían planteado la posibilidad de liberar el rehén. Será solo a partir del comunicado número 8, del 24 de abril, cuando las Brigadas Rojas empezaron a barajar la hipótesis de un intercambio de algunos prisioneros terroristas detenidos a cambio de la liberación de Aldo Moro. Sin embargo, no se llegó ni siquiera a abrir un proceso de negociación desestimándose rápidamente esa opción por parte del gobierno.

Todos los periódicos publicaron la carta del presidente de la Democracia Cristiana, pero la casi totalidad de ellos advirtió de que se trataba de un texto escrito por un hombre mermado en su voluntad por el cautiverio. Il Giornale rechazó con vehemencia lo que proponía Aldo Moro, desautorizando todo lo que llegaba de la mano de los terroristas, aunque la carta estuviera firmada por el político. Con un artículo en dos columnas titulado «El sello estalinista», Domenico Bartoli zanjaba el tema declarando que ese mensaje no tenía ningún tipo de valor. El periodista decía: «ignoramos qué métodos hayan elegido los secuestradores para doblegar la voluntad de Moro, pero podemos afirmar con firmeza que solo la coacción puede haberle obligado a escribir lo que escribió» ${ }^{18}$.

El Corriere della Sera también dudaba de la autenticidad de la carta y se preguntaba: «¿Quién escribió esa carta? ¿La escribió Aldo Moro presidente de la Democracia Cristiana, estadista, máximo mediador e inspirador de la política italiana, prudente estratega? ¿O la escribió un hombre con el mismo nombre y la misma cara, Aldo Moro, pero reducido a la impotencia en un cruel cautiverio, aislado, quizá aturdido por las drogas? ${ }^{19}$. La Repubblica, el 30 de marzo, bajo el elocuente título «Esas palabras no son suyas», apuntaba a que los brigadistas habían utilizado la tortura, «aunque sea psicológica», como método persuasivo para que Aldo Moro se hubiera visto obligado a redactar esa carta ${ }^{20}$.

El presidente de la Democracia Cristiana, en realidad, creía estar escribiendo a su compañero de partido «de manera muy reservada» ${ }^{21}$, tal y como él mismo especificaba en su texto; sin embargo los terroristas no res-

\footnotetext{
se limitarán a analizar la situación, proporcionando un escenario en el cual parecía que era únicamente Aldo Moro quien acusaba a la clase política italiana mientras que ellos simplemente enseñaban esa contradicción tal y como aparece analizado en Marletti, 1979, p. 209.

18 Domenico Bartoli, «Il sigillo stalinista», Il Giornale, 31-III-1978.

19 «Ma la Repubblica non sarà mai prigioniera», Corriere della Sera, 30-III-1978.

20 «Quelle parole non sono le sue», La Repubblica, 30-III-1978.

21 Moro, 2003, p. 13.
} 
petaron su petición de privacidad y difundieron el contenido de la misiva, lo cual llevó a dos consecuencias muy graves. Por un lado, tal y como hemos analizado, dio pie a la desautorización de todo lo que el prisionero escribiría a partir de ese momento. Moro será descrito por la prensa como una persona incapaz de expresar su libre pensamiento, totalmente a merced de sus captores. Se le llegará a describir como una persona trastornada por el cautiverio y, por lo tanto, incapaz de redactar algo sensato. Hay un punto en la carta, donde Moro reconoce encontrarse «bajo un control total e imprevisible». Esa frase será la más utilizada para justificar que el rehén no se encontraba en uso de sus plenas facultades. Visto hoy, parece un burdo error por parte de un estratega tan brillante como fue Aldo Moro, sin embargo, repetimos, su carta iba dirigida exclusivamente al ministro Francesco Cossiga, y si bien era presumible que su contenido pudiera llegar a los demás compañeros de partido, lo que Moro desconocía es que las Brigadas Rojas decidieran difundir a la prensa sus palabras.

Por otro lado, la segunda consecuencia fue que, a partir de ese momento, la prensa se dedicó a entregar a los lectores una especie de novela policiaca en la que cada uno podía conjeturar sobre lo ocurrido ${ }^{22}$. Eugenio Scalfari, en la portada de La Repubblica, lo llegó a expresar bastante bien el 31 de marzo de 1978: «la fantasía de los italianos se está ejercitando en estas horas sobre un dilema: ¿Moro escribió la carta a Cossiga libremente u obligado? En esta segunda hipótesis, ¿cuáles son los medios utilizados por sus carceleros?» ${ }^{23}$. El Corriere della Sera consultó con un experto psico-grafólogo, quien declaró que en la misiva aparecían gestos evidentes de que Aldo Moro había sido obligado a transcribir un texto redactado por otra persona. Su grafía nerviosa revelaba su complicada condición psicológica ${ }^{24}$.

El 4 de abril llegó la segunda carta de Aldo Moro, esta vez dirigida al secretario de la Democracia Cristiana, Benigno Zaccagnini. Una vez más, el supuesto apagón informativo no se llevó a cabo, aunque en realidad se informó sin llegar realmente a informar, basándose más en conjeturas que en hechos contrastables. Según el Corriere della Sera lo que llegaba de la prisión brigadistas era «una carta desde el infierno» ${ }^{25}$. Il

\footnotetext{
22 Bechelloni, 1978, p. 6.

23 Scalfari, Eugenio, «Senza pietà e senza giustizia», La Repubblica, 31-III-1978.

24 «Nascosti due messaggi fra le righe delle pagine scritte dal prigioniero», Corriere della Sera, 31-III-1978.

25 «Una lettera dall'inferno», Corriere della Sera, 6-IV-1978.
} 
Giornale reiteraba su rechazo: «no tenemos nada que decir sobre esta segunda carta de Aldo Moro por la sencilla razón de que no es suya» ${ }^{26}$. El descrédito sobre todo lo que provenía de la «prisión del pueblo», tal y como los brigadistas se referían en sus escritos al lugar donde mantenían al secuestrado, hizo que poco a poco no se contara con Aldo Moro como sujeto activo de una posible negociación ${ }^{27}$. Se llegó a declarar que, probablemente, el rehén podía llegar a «confesar hechos nunca ocurridos» tal y como apareció en un artículo de La Repubblica del 12 de abril de $1978^{28}$. Moro había sido «demolido» ${ }^{29}$, había «casi muerto, por lo menos políticamente» ${ }^{30}$. Se llevó a cabo, pues, una especie de «limitación informativa», negándole al secuestrado toda credibilidad. Se publicaban sus cartas pero se desestimaban todas. No se hacía lo mismo con los comunicados de los brigadistas, que aparecían, a veces en su totalidad, otras en versión reducida, pero al fin y al cabo incluyendo los puntos más importantes, en la prensa italiana sin que eso conllevara una crítica sobre la credibilidad de los terroristas ${ }^{31}$.

En ese momento, dos semanas después del día del secuestro, estaban por un lado los terroristas y por el otro el Gobierno, cuyos representantes declaraban la imposibilidad de negociar con las Brigadas Rojas. Podríamos decir que «el caso Moro» había terminado ya a principios de abril. Todo lo que ocurrió de ahí en adelante no fue más que un triste

26 «Il ricatto delle BR», Il Giornale, 5-IV-1978.

27 Se repite constantemente que lo que escribe Aldo Moro no se le puede atribuir moralmente a él ya que seguramente el estadista había sido drogado o amenazado para que escribiera esas cosas. Véase por ejemplo: «Non è moralmente ascrivibile a Moro», L'Unità, 5-IV-1978; «Quelle parole non sono credibili», La Repubblica, 5-IV-1978; Leo Valiani, «Ma quale processo?», Corriere della Sera, 6-IV-1978; Gianfranco Pizzesi, «La forza della dignità», Corriere della Sera, 7-IV-1978; Cesare Medail, «Non scrive così per paura», Corriere della Sera, 26-IV-1978.

${ }_{28}$ Giampaolo Pansa, «E se Moro confessasse anche fatti mai accaduti?», La Repubblica, 12-IV-1978.

29 Geno Pampaloni, «La mostruosa demolizione di Moro», Il Giornale, 13-IV-1978.

30 Sandro Viola, «In 20 giorni hanno ucciso un leader», La Repubblica, 5-IV-1978.

31 Ejemplos de la reproducción de los comunicados de las Brigadas Rojas en su totalidad o a modo de resumen son: «Nel loro messaggio», L'Espresso, 2-IV-1978; «Il nuovo volantino delle BR», La Repubblica, 11-IV-1978; «I principali brani del messaggio n. 5 e dello scritto di Moro», L'Unità, 11-IV-1978; «Le Brigate Rosse: Il processo è finito, Aldo Moro è stato condannato a morte», Corriere della Sera, 16-IV-1978; «La spietata sentenza delle BR», La Repubblica, 17-IV-1978; «BR: «concludiamo eseguendo la sentenza»», Avanti!, 6-V-1978. 
intento de estirar algo que no parecía tener ninguna solución. Probablemente es por eso que los periódicos dejaron de informar. No lo hicieron de manera real, mantuvieron una preponderancia abrumadora de noticias sobre el presidente de la Democracia Cristiana, sobre las Brigadas Rojas, sobre aquellos momentos difíciles que estaba viviendo el país, pero dejaron de escribir algo realmente interesante y novedoso. Ninguna noticia de calidad perturbaba ese clima ya de por sí enrarecido: por un lado, los terroristas difundían sus documentos llenos de obviedades, alegatos a favor de una causa cada vez más alejada del mundo real. Por el otro, Aldo Moro, desprestigiado por los suyos y por la prensa, no era más que un títere en manos de sus captores; por último, estaba una clase política enrocada en el más absoluto rechazo a cualquier tipo de diálogo con los brigadistas, a pesar de que esa actitud conllevara el abandono de su compañero.

El debate sobre la utilidad/posibilidad de reducir el espacio informativo preparado, se podría decir casi servido, por los terroristas no tuvo éxito. Se siguió publicando todo lo que salía de la «prisión» y, a falta de verdaderas noticias, se les concedió a los secuestradores el privilegio de tener a su disposición la mayoría de los medios de comunicación italianos para difundir sus mensajes ${ }^{32}$. Además, una vez despojado a Aldo Moro de todo tipo de credibilidad, la mayoría de la prensa se alineó con el Gobierno haciéndose eco de la posición según la cual no se iba a pactar bajo ningún concepto con los terroristas. El trágico epílogo del secuestro llevó a Aldo Moro a ser considerado una víctima necesaria para que se salvara la democracia.

\section{El secuestro del juez D'Urso y el chantaje de los terroristas}

En los meses que siguieron al secuestro de Aldo Moro, que había empezado el 16 de marzo de 1978 con el asesinato de los agentes que lo escoltaban y que había acabado con su muerte el 9 de mayo de ese mismo año, la prensa no dejó de comentar el suceso relativo al ya ex presidente de la Democracia Cristiana y los siguientes atentados llevados a cabo por la banda terrorista.

32 Valgan como ejemplo los siguientes artículos: «Ecco il testo dello scritto su Taviani. Gli amici: «Un Moro irriconoscibile»», Corriere della Sera, 11-IV-1978; «La lettera di Moro a Zaccagnini», Avanti?, 23-IV-1978; «Sei tragiche lettere», L'Unità, 30-IV-1978. 
A pesar de que un experto en terrorismo como Walter Laqueur, en una entrevista al Corriere della Sera, asegurara que «aunque vuelvan a disparar, las Brigadas Rojas ya están muertas ${ }^{33}$, la verdad es que la preocupación era elevada y la potencia militar de los terroristas no parecía flaquear. A nivel informativo, el binomio terrorismo-medios de comunicación era algo que preocupaba ya a nivel internacional. Un ejemplo de ello fue la conferencia europea organizada en Londres por el Instituto Internacional de Prensa en el mes de noviembre de ese mismo año 1978. En la ponencia inaugural, el ministro del Interior británico afirmó que «el terrorismo es una forma de teatro político y los terroristas utilizan los medios de comunicación para explotar asuntos de naturaleza pública en forma violenta» ${ }^{34}$.

En Italia, mientras tanto, la reacción popular, a pesar de haber sido tajante en contra de lo ocurrido con Aldo Moro, no se compartía por la totalidad de la población. De hecho, persistía una masa crítica a la que le costó condenar el atentado ${ }^{35}$.

El 12 de diciembre de 1980 la organización terrorista secuestró al juez Giovanni D’Urso, director del Departamento III de la Dirección general de los Institutos de Prevención y Condena del Ministerio de Justicia. Según Mario Moretti esa fue la «obra maestra» del grupo que él mismo lideraba en ese momento. Con ella los brigadistas consiguieron el cierre de una cárcel y la difusión mediática de unos comunicados redactados por terroristas detenidos, es decir la totalidad de las peticiones que habían formulado ${ }^{36}$.

En el primer comunicado de reivindicación, las Brigadas Rojas pedían el «cierre de Asinara», la cárcel de máxima seguridad que albergaba a terroristas y donde, según los brigadistas, en su lógica de derro-

${ }^{33}$ Piero Ostellino, «Anche se spareranno ancora, le Brigate Rosse sono morte», Corriere della Sera, 13-X-1978.

34 Ahora en Benito, 1986, pp. 117-118.

35 Sobre este tema el autor de este artículo ha realizado entrevistas a ex militantes de los grupos extraparlamentarios italianos (Lotta Continua, Potere Operaio, Avanguardia Operaia) que, en algunos casos no demasiado aislados, le han confesado no haberse apenado mucho por lo que le ocurrió a Aldo Moro, aunque es verdad que si por un lado se aprobaba el secuestro, en menor porcentaje se era partidarios de la eliminación del político. Entrevistas realizadas en las ciudades de Milán, Turín, Novara y Vigevano en el mes de diciembre de 2014. El estudio completo sobre dichas entrevistas está en prensa.

36 Moretti, 2002, p. 221 y ss. 
tar a un Estado opresor, se llevaban a cabo «la represión» y «la barbarie imperialista» ${ }^{37}$.

El ministro de Justicia, Adolfo Sarti, anunció que se llevaría a cabo esa medida, especificando que se trataba de una decisión tomada tiempo atrás, y que por lo tanto, tal y como matizó también el jefe del Gobierno, Arnaldo Forlani, no tenía ninguna vinculación con las exigencias brigadista $^{38}$. Queda claro que la actuación del gobierno con Giovanni D’Urso difirió bastante de la que se llevó a cabo con Moro. Toda la firmeza y el rechazo a la negociación con los brigadistas que se puso en marcha con el secuestro del político democristiano, en este otro caso brillaron por su ausencia.

A pesar de que el gobierno optara por el cierre de la prisión, el chantaje de los terroristas no paró. El 28 de diciembre unos reclusos del penitenciario de Trani - casi todos detenidos por crímenes de terrorismo - tomaron a diecinueve agentes como rehenes antes de ser reducidos por la fuerza. Durante el motín, los revoltosos redactaron unos comunicados pidiendo varios cambios en el sistema penitenciario. Las Brigadas Rojas, en solidaridad con los compañeros detenidos, pero sobre todo debido a un reajuste interno que estaba estableciendo nuevos equilibrios en la banda ${ }^{39}$, vincularon la liberación del juez D'Urso con la publicación de esos textos en los principales periódicos italianos. Esa petición quedaba clara en el comunicado brigadista número 6, del 29 de diciembre, donde se declaraba que «los comunicados tienen que ser publicados de inmediato y de manera íntegra», pero aún quedaba más claro en el comunicado número 8, del 4 de enero de 1981. En éste se condenaba a muerte al rehén, pero se especificaba que, si los medios de comunicación difundían los comunicados redactados por los detenidos, ellos indultarían a D'Urso. El periodismo italiano se vio sumido en un gran dilema: ceder a la petición de unos criminales, pero probablemente salvar la vida de un hombre, o rechazar esa coacción, y poner en peligro la vida de una persona ${ }^{40}$. La estrategia de los terroristas es un claro ejemplo de atribución de culpabilidad: los brigadistas quieren que los medios de comunicación sean considerados los verdaderos culpables en

37 Comunicados n. ${ }^{\circ} 1$ y 2 del secuestro D’Urso, difundidos ambos el 13 de diciembre de 1980, en Progetto Memoria, 1996, pp. 198-223.

38 Clementi, 2007, p. 276.

39 Galfré, 2014, p. 27.

40 Progetto Memoria, 1996, p. 215. 
caso de que D'Urso fuera asesinado, ya que fueron ellos los que no accedieron a satisfacer las peticiones exigidas por su liberación e impulsaron su muerte ${ }^{41}$.

El 31 de diciembre, como respuesta a la represión del motín, los brigadistas mataron a Enrico Galvaligi, responsable de los servicios de seguridad en las cárceles y quien había ordenado la intervención en la prisión de Trani.

La situación, ya de por sí difícil, se complicó aún más cuando dos periodistas de la revista L'Espresso, Mario Scialoja y Giampaolo Bultrini, consiguieron una entrevista con los secuestradores del juez, anunciada el 31 de diciembre de 1980 , pero publicada el 11 de enero de $1981^{42}$. La magistratura los mandó detener dando pie a un largo debate sobre deontología periodística. Según Leo Valiani, del Corriere della Sera, Scialoja (el autor de la entrevista, su compañero Bultrini fue quien logró el contacto con los terroristas) había cometido un grave error al no avisar a la policía para que le siguieran y descubrieran donde se encontraba el juez ${ }^{43}$. Según La Repubblica el problema no era tan sencillo, ya que avisar a las Fuerzas de Seguridad del Estado «hubiera podido empeorar la situación y producir eventos nefastos ${ }^{44}$. Il Manifesto estaba en desacuerdo con la intervención de la magistratura, al considerar la detención de los periodistas una mera «prueba de fuerza» de poca utilidad ${ }^{45}$. L'Unità se desmarcaba totalmente de lo ocurrido atacando a sus autores ya que «una primicia periodística no legitima ninguna connivencia con una banda criminal» ${ }^{46}$. La Repubblica publicó una entrevista a Livio Zanetti, director de L'Espresso, la revista incriminada, y Vittorio Gorresio, director de La Stampa de Turín. Según Gorresio «el periodista no tiene que convertirse en un 007» y cuando lo hace es solo para vender más periódicos y en ningún caso para ayudar en la investigación. En cambio, Zanetti afirmaba que, en los últimos tiempos, «el periodista ha tenido que sustituir a la autoridad investigadora» con cada vez más frecuencia, hecho que consideraba de utilidad para la comunidad ${ }^{47}$.

\footnotetext{
41 Bandura, 2004, p. 134.

42 Sobre la entrevista a las Brigadas Rojas véanse Gotor, 2011, pp. 345-346 y Mastromatteo, 2007, pp. 236-247.

${ }^{43}$ Leo Valiani, «I giornalisti di fronte agli assassini», Corriere della Sera, 2-I-1981.

44 «Se capitasse a uno di noi», La Repubblica, 2-I-1981.

45 «Arrestato il giornalista Scialoja», Il Manifesto, 2-I-1981.

46 «Che c'entra la libertà di stampa?», L'Unità, 3-I-1981.

47 Alberto Stabile, «Giornalista vil razza dannata a che prezzo faresti uno scoop?», $L a$ Repubblica, 5-I-1981.
} 


\section{Bajo la amenaza de las Brigadas Rojas}

A partir del 6 de enero de 1981, algunos periódicos empezaron a publicar artículos en los que se perfilaba la opción de llevar a cabo un «apagón informativo» como respuesta a las exigencias de los terroristas de publicar los comunicados de los detenidos de la cárcel de Trani. Primero fue Il Tempo, rotativo romano de orientación conservadora, que declaraba que no se iban a publicar las proclamas y las amenazas brigadistas ${ }^{48}$; el director de La Repubblica, Eugenio Scalfari, aun defendiendo el derecho a la información, rechazaba dar visibilidad a aquellos criminales"9; el Corriere della Sera, por su parte, optó por el silencio. La dirección del periódico publicó un comunicado para sus lectores en el que se decía que:

De acuerdo con el grupo editorial [Rizzoli] e informado el Comité de redacción, [el periódico] ha decidido a partir de hoy llevar a cabo un silencio total sobre las peticiones de los terroristas secuestradores del juez D'Urso [...] Que sepa el lector que esta decisión no le privará de ninguna noticia: haremos desde hoy un diario, si cabe, aún más rico e informado eliminando de la crónica sobre terrorismo sólo aquella parte de puro chantaje que intenta envenenar y turbar la verdad ${ }^{50}$.

Il Giornale también decidió «echar el cierre» ${ }^{51}$, aunque esa decisión, según su director, Indro Montanelli, significaba «casi seguramente la muerte del juez D'Urso» ${ }^{52}$. L'Unità rechazaba «hacerse portavoz del terrorismo» y subrayaba cómo en tan solo cuatro días, es decir desde la detención del periodista Scialoja a la difusión del comunicado número 8 de las Brigadas Rojas, en el mundo periodístico italiano había ocurrido algo «nuevo y profundo»: se había pasado de la publicación de la larga entrevista a las Brigadas Rojas publicada por L'Espresso a la decisión, casi unánime, de dejar de suministrar noticias sobre los documentos de los brigadistas $^{53}$. Una parte de la prensa italiana parecía posicionarse a favor de

\footnotetext{
48 Gianni Letta, «Staccare la spina», Il Tempo, 6-I-1981.

49 Eugenio Scalfari, «Proclami no, notizie sì», La Repubblica, 6-I-1981.

50 «A lettori: il Corriere ha deciso il silenzio», Corriere della Sera, 6-I-1981.

51 «Avviso ai lettori: mai più messaggi delle Brigate Rosse», Il Giornale, 6-I-1981.

52 Indro Montanelli, «Uomini e topi», Il Giornale, 6-I-1981.

53 «La stampa rifiuta di farsi portavoce del terrorismo», L'Unità, 6-I-1981.
} 
aquel «apagón informativo» que, unos años antes, había teorizado Marshall McLuhan y que no se llevó del todo a cabo durante el secuestro de Aldo Moro.

Las buenas intenciones, sin embargo, no fueron acompañadas por su aplicación real. Ya lo había vaticinado, el 7 de enero, Mauro Paissan, de Il Manifesto, declarando inviable la opción de no informar, ya que los lectores se hubieran redirigido hacia otros rotativos menos estrictos con esa especie de autocensura ${ }^{54}$. El primero en no estar de acuerdo con la interrupción de información era el Avanti!. El director del periódico del Partido Socialista Italiano declaraba que lo único que había que silenciar eran las polémicas y las divisiones entre los partidos políticos y el mundo de la información, desmarcándose de la estrategia de los demás diarios favorables a la no-información ${ }^{55}$. La Stampa, por su parte, decidió seguir informando con normalidad, sin aplicar ninguna censura. Giuliano Zincone, director de un periódico menor, Il Lavoro, de Génova, presentó su renuncia al cargo por las discrepancias con la línea editorial propuesta por Rizzoli, grupo del que su periódico formaba parte. Unos años más tarde fue el mismo Zincone quien, en una larga entrevista con Sergio Zavoli, explicó su posición de entonces:

Encontré una contradicción muy extraña en la prensa de aquel periodo. Vi que, en general, se privilegiaba lo que convenía más a los terroristas: la ferocidad de sus hazañas, la llamada potencia geométrica de sus asaltos, y en cambio se ponía entre paréntesis el lado más vulnerable de su actividad, es decir, los documentos. Mi posición era la siguiente: dar menos espacio, y de esta manera menospreciar, a la violencia militar de los terroristas que lamentablemente hacían prosélitos, y debatir y discutir sus documentos que [...] representaban el lado más frágil de su organización ${ }^{56}$.

Los demás periódicos que estaban de acuerdo con publicar eran $L a$ Repubblica, Il Messaggero, La Nazione, Il Giorno, Il Resto del Carlino, Il Manifesto y Lotta Continua.

\footnotetext{
54 Mauro Paissan, «Uomini e giornalisti», Il Manifesto, 7-I-1981.

55 Ugo Intini, «Il silenzio più utile è su quanto esaspera divisioni e tensioni», Avanti!, 6-I-1981.

56 Zavoli, 1992, p. 414.
} 


\section{Utilidad o perjuicio}

La primera consecuencia del posible apagón informativo fue la poca relevancia que una parte de la prensa dio a la carta que la mujer de Giovanni D'Urso (probablemente la única víctima del «apagón informativo») escribió a su marido a través de la agencia periodística ANSA, el día 6 de enero de 1981. El Corriere della Sera publicó un resumen de tan solo doce líneas ubicándolo en una página interna. El director de La Repubblica, Eugenio Scalafari, se mostró dolido por esa ocultación y por ese cambio tan repentino y sospechoso que había dado la prensa italiana, avisando del peligro que podía conllevar que todo el mundo dejara de infor$\operatorname{mar}^{57}$.

El 8 de enero el Corriere della Sera informó sobre la visita que unos diputados del Partido Radical habían realizado al penitenciario de Trani. En el artículo se leía que las peticiones de los brigadistas en libertad coincidían con las de los detenidos:

Los terroristas hablan todavía de suspensión de la condena a muerte, pero imponen sus duras condiciones: la condena a muerte será suspendida sólo si se publican integralmente en los mayores órganos de información tres comunicados: el primero, un documento-proclama entregado al director de la cárcel, el segundo, aquel que dieron a los parlamentarios radicales. Además piden la publicación de sus peticiones-chantaje para que D'Urso sea liberado ${ }^{58}$.

El peligro que se estaba corriendo en aquel momento fue percibido por Saverio Vertone quien, en las páginas de L'Unità, denunciaba que «la prensa se está progresivamente cerrando en un círculo vicioso y parece empeñada en informar especialmente sobre ella misma» ${ }^{59}$. El error era justamente ese: olvidarse de que había un hombre en manos de unos asesinos y utilizar un amplio espacio informativo - quizá excesivo- para debatir sobre si era correcto o no publicar los comunicados.

El 10 de enero las Brigadas Rojas difundieron el mensaje número 9, el penúltimo de la campaña D’Urso. En el texto aparecía un ultimátum:

57 Eugenio Scalfari, «Che buio se tutti staccano la spina», La Repubblica, 7-I-1981.

58 «Ore tese e confuse sulla sorte di D’Urso. La vita appesa a un filo che parte da Trani», Corriere della Sera, 9-I-1981.

59 Saverio Vertone, «Un giornalismo che fa velo alla realtà», L'Unità, 7-I-1981. 
«Si dentro de cuarenta y ocho horas de la publicación de este comunicado no leemos de manera íntegra en los mayores periódicos italianos los comunicados que desde Trani y Palmi ${ }^{60}$ han sido emitidos, procederemos a ejecutar a D'Urso» ${ }^{61}$. Al día siguiente todos los periódicos informaron del terrible chantaje al que se veía sometida la prensa italiana. La división entre quienes no querían ceder a las exigencias de los brigadistas y los que, por humanidad, y en la esperanza de salvar la vida al juez secuestrado, decidieron ceder a las Brigadas Rojas, creó muchas polémicas entre los periodistas en las que la emotividad y la histeria suplantaron a la racionalidad ${ }^{62}$.

Leonardo Sciascia hizo un llamamiento a los periódicos para que publicaran lo que pedían los terroristas. Alrededor de 70 personas entre periodistas y personalidades destacadas (entre las cuales se encontraba la viuda de Aldo Moro) apoyaron la petición del escritor ${ }^{63}$. Il Giornale salía a la venta con una columna en la que se consideraba a D'Urso ya cadáver y por eso se consideraba inútil cualquier concesión a los brigadistas $^{64}$. Eugenio Scalfari, en La Repubblica, rechazaba el «chantaje en nombre de otras vidas» ya que, de realizarse ese acto de debilidad, vaticinaba un periodo de terror aún más grave que el que se estaba viviendo $^{65}$. El Corriere della Sera proclamaba que «no se negocia con enemigos feroces y despiadados» y consideraba que una rendición hubiese impulsado a los asesinos a cometer más delitos ${ }^{66}$. L'Unità, por su parte, al rechazar también el chantaje, acusaba con dureza a quienes se habían doblegado a las peticiones de los terroristas, especialmente a los socialistas ${ }^{67}$. Efectivamente, al otro lado estaba el periódico del Partido Socialista Avanti! que ya el día 10, antes de que las Brigadas Rojas difundieran su comunicado número 9, se había declarado favo-

${ }^{60}$ Palmi es una cárcel en la que se encontraban muchos brigadistas detenidos, entre otros Renato Curcio, el líder fundador de las Brigadas Rojas, y de donde también salieron unos comunicados redactados por terroristas.

${ }^{61}$ Comunicado n. ${ }^{\circ} 9$ del secuestro D’Urso, difundido el 10 de enero de 1981, en Progetto Memoria, 1996, p. 217 y ss.

62 Murialdi, 1981, pp. 145-152.

${ }_{63}$ El llamamiento de Sciascia se produjo los días 10 de enero y se reiteró el día 12.

64 Indro Montanelli, «Con angoscia ma «no»», Il Giornale, 11-I-1981.

65 Eugenio Scalfari, «No al ricatto in nome di altre vite», La Repubblica, 11-I-1981.

${ }^{66}$ Leo Valiani, «I ricattatori di fronte alle loro responsabilità», Corriere della Sera, 11-I-1981.

67 «Per salvare la vita di tutti», L’Unità, 11-I-1981. 
rable a la publicación de los documentos si eso podía «servir para salvar al magistrado ${ }^{68}$. Junto con ese periódico se situaban, entre otros, Lotta Continua, que sin tapujos admitía «estaba en juego la vida de un hombre y por eso había que publicar» ${ }^{69}$, Il Manifesto, los radicales con su radio y otros periódicos menores mantenían su posición de publicar, tal y como se ha analizado más arriba. Fue justamente el Partido Radical el que, el 12 de enero, dio otro golpe de efecto en ese delicado asunto cediendo un breve espacio televisivo a la familia del juez. La hija, de apenas diecinueve años, leyó el documento del que las Brigadas Rojas habían pedido su máxima difusión, y donde su padre era definido como «verdugo $»^{70}$. Algunos medios de comunicación reaccionaron expresando su más profundo rechazo hacia lo que se acababa de retransmitir: una joven desesperada obligada a ofender a su propio padre por televisión. Laura Betti, en L'Unità, escribió un artículo muy duro donde declaraba que esa imagen no era digna de ver. El periódico comunista, en otros artículos, declaró su «desprecio» hacia Pannella definiéndolo como «aliado de los brigadistas»71. La Repubblica llegó a hablar de complicidad con los asesinos por parte de «quienes ofrecieron la posibilidad material» de trasmitir los mensajes de los terroristas $^{72}$. Este periódico, se descubrirá más tarde, fue uno de los que más presiones recibió por parte de los brigadistas, los cuales le llegaron a imponer dónde tenía que aparecer el comunicado (en la portada, obviamente), el título y el formato ${ }^{73}$.

En medio de estas polémicas, pasó algo que hizo que algunos periódicos reaccionaran publicando los comunicados. El 13 de enero el direc-

68 Ugo Intini, «La carta non vale la vita umana», Avanti!, 10-I-1981.

69 «Se entro 48 ore...», Lotta Continua, 11-12-I-1981.

70 En realidad, tal y como explicaría años después en una entrevista a Sergio Zavoli (op. cit., p. 404) el radical Franco Spadaccia, el partido había cedido ese espacio para que la familia D'Urso hiciese una apelación a los secuestradores del juez y nada más. De hecho, la intervención de la hija Lorena había empezado de esa manera, fue de repente cuando sacó el comunicado y lo leyó. Ya era demasiado tarde para interrumpir la retransmisión.

${ }^{71}$ Laura Betti, «Quelle immagini che rifiuto di vedere», L'Unità, 15-I-1981; «Ignobile Pannella: induce la figlia di D'Urso a chiamare boia il padre», L'Unità, 13-I-1981; Lombardo Radice, «Il «compagno» dei brigatisti perde la testa: gli assassini sono i giornalisti», L'Unità, 13-I-1981. 1981.

${ }^{72}$ Eugenio Scalfari, «Ma stavolta non sarà come l'8 settembre», La Repubblica, 13-I-

73 Miguel Gotor, «La lezione di D’Urso», La Repubblica, 28-IX-2011. 
tor de Avanti! recibió una carta de Giovanni D'Urso. En ella, el magistrado rogaba que se publicara lo que pedían los brigadistas recalcando el «carácter exclusivamente humanitario» de dicho gesto ${ }^{74}$. Al día siguiente, Il Secolo XIX e Il Messaggero decidieron publicar los comunicados ${ }^{75}$.

Solo un día más tarde las Brigadas Rojas difundieron el último comunicado de la «campaña D’Urso» dando por válida la publicación en los dos periódicos: «Los objetivos políticos y materiales de la campaña de ataque empezada con D'Urso se han conseguido; el movimiento de los proletarios prisioneros, el movimiento revolucionario y las BR han conseguido una gran victoria. Considerando todo esto, la justicia proletaria aprueba un acto de magnanimidad. La sentencia está suspendida y el prisionero D'Urso va a ser puesto en libertad» ${ }^{76}$.

Estas palabras desataron una gran euforia, que se prolongó al día siguiente cuando efectivamente el juez fue liberado. La reacción de los periódicos, sin embargo, no fue solamente de júbilo; cada uno se atribuyó el éxito final del secuestro. Quien se había mantenido firme en la intención de no publicar los documentos de los terroristas acusaba al otro bando de connivencia con el enemigo, los favorables a la publicación, por otra parte, consideraban inmorales a quienes se habían negado a intentar por todos los medios salvar la vida de un hombre.

\section{Conclusiones}

En Italia, entre 1978 y 1981, se asistió en dos ocasiones al debate sobre la posibilidad de que los medios de comunicación limitasen su actividad informativa. Tal y como hemos analizado en estas páginas, se trató de un proceso nada homogéneo, en el cual se desataron ásperas polémicas y duros enfrentamientos. En ambos casos, la disyuntiva entre informar o dejar de hacerlo surgió como consecuencia de dos secuestros perpetrados por el grupo terrorista Brigadas Rojas.

\footnotetext{
${ }^{74}$ La carta será publicada el 14 de enero en Avanti! Bajo el título a siete columnas «La lettera del giudice».

75 «Un gesto sofferto per la vita umana», Il Messaggero, 14-I-1981; «Scaduto l'ultimatum BR. D'Urso è vivo e invoca la pubblicazione dei proclami», Il Secolo XIX, 14-I-1981.

${ }^{76}$ Comunicado n. ${ }^{\circ} 10$ del secuestro D'Urso, difundido el 14 de enero de 1981, en Progetto Memoria, 1996, p. 220.
} 
Durante dichos secuestros, el de Aldo Moro y el de Giovanni D’Urso, los periodistas entablaron unas acaloradas discusiones desde las páginas de sus periódicos defendiendo sus diferentes posturas. Unos no consideraban ético convertirse en portavoces de los terroristas y por lo tanto condenaban la publicación de lo que salía de la «prisión del pueblo», otros, en cambio, valoraban positivamente la difusión de cualquier noticia, al ser una tarea propia del buen periodista y un deber de cara a sus lectores. Por un lado, estaba la vida de dos hombres, con lo que había que añadir las comprensibles presiones por parte de sus familias; por otro lado, estaba el deber de defender la libertad, considerando que, cediendo aunque fuera solo una vez a los terroristas, se hubiera arrastrado a la prensa italiana a un bucle interminable que, además, no habría garantizado la libertad de los secuestrados.

Los dos rehenes sufrieron un diferente trato: a Moro se le tildó desde el principio de persona incapacitada para escribir algo sensato y víctima de una voluntad superior que le obligaba a redactar lo que en realidad querían los brigadistas. Giovanni D'Urso pasó su cautiverio en segundo plano, quizá porque no tuvo que escribir apenas cartas, y probablemente también porque no era un personaje de la relevancia de Aldo Moro. Pero cuando se puso a redactar una carta desesperada en la que se pedía que los periódicos cedieran a las exigencias de los terroristas, nadie le acusó de ser un pelele en manos de unos asesinos manipuladores.

El «apagón informativo» que se planteó repetidas veces en esos días no se llevó a cabo. En realidad se trataba de dos «apagones» diferentes. Con Aldo Moro se discutía sobre la conveniencia de ser una caja de resonancia de los terroristas cuestionando especialmente los escritos redactados por Aldo Moro, tras cuya autoría muchos veían a los mismos brigadistas. Con Giovanni D’Urso el problema era incluso más grave: los brigadistas chantajearon directamente a los medios de comunicación pretendiendo manipularlos y hasta casi dirigirlos a su antojo.

Dicho esto, y tras haber analizado un elevado número de periódicos y de artículos, podemos concluir que el rechazo por parte de los periodistas a publicar lo que enviaban los terroristas se limitó, en la mayoría de los casos, a amagos que se mantuvieron más bien a un nivel teórico. En el momento de decidir si difundir determinadas noticias, casi siempre se optó por su divulgación. Solo con la petición de publicar los textos redactados por terroristas detenidos en la cárcel de Trani se llegó a una verdadera ruptura entre un bando y otro. La firmeza, una de las palabras más utilizadas durante esos dos secuestros, pareció aplicarse contra los dos 
rehenes más que contra los terroristas. Aldo Moro no tuvo la posibilidad de defenderse al quedar desautorizado desde el principio por compañeros y medios de comunicación y perder así todo tipo de credibilidad. La mujer de D'Urso logró escaso espacio en los medios. Solo se le recuerda una carta en la que pidió la liberación de su marido pero que tuvo un eco muy limitado a nivel mediático. Quien sí consiguió mantener en vilo a la prensa italiana fueron los brigadistas. A pesar del órdago lanzado por los terroristas, ni el gobierno ni la mayoría de los partidos políticos aceptaron negociar con ellos. En el secuestro de Giovanni D’Urso, los brigadistas vieron satisfechas todas sus peticiones sin la necesidad de matar al rehén. En ambos casos las Brigadas Rojas consiguieron fracturar la unidad de los medios de comunicación y, asimismo, a la sociedad italiana, logrando así uno de los principales objetivos no solo de esta banda armada sino de toda organización terrorista.

\section{Bibliografía}

BECHELlONI, Giovanni, «Notizia o interpretazione?», en Problemi dell'informazione, Il Mulino, Bologna, n. 2, 1978, pp.171-178.

BANDURA, Albert, «The role of selective moral disengagement in terrorism and counterterrorism», en MOGHADDAM, Fathali y MARSELLA, Anthony, Understanding Terrorism, American Psychological Association, Washington, 2004, p. 121-150.

BENITO, Ángel «Terrorismo y medios de comunicación», en COLECTIVO MIGUEL DE UNAMUNO, Escritos sobre la tolerancia, Editorial Pablo Iglesias, 1986, pp. 117-118.

BOATTI, Giorgio: Piazza Fontana, Einaudi, Turín, 2009.

CLEMENTI, Marco, Storia delle Brigate Rosse, Odradek, Roma, 2007.

DONDI, Mirco: L'eco del boato: storia della strategia della tensione, 1965-1974, Laterza, Roma-Bari, 2015.

FERRARESI, Franco, Minacce alla democrazia. La destra e la strategia della tensione in Italia nel dopoguerra, Feltrinelli, Milano, 1995.

GALFRÉ, Monica, La guerra è finita, Laterza, Roma-Bari, 2014.

GLUCKSMANN, André, El discurso del odio, Taurus, Madrid, 2005.

GONZÁLEZ CALLEJA, Eduardo, El Laboratorio del miedo, Critica, Barcelona, 2013.

GOTOR, Miguel, Il memoriale della Repubblica, Einaudi, Torino, 2011.

GRINER, Massimiliano: Piazza Fontana e il mito della strategia della tensione, Lindau, Torino, 2011. 
GROSSI, Giorgio, Rappresentanza e rappresentazione. Percorsi di analisi ell'interpretazione tras mass media e sistema politico in Italia, Franco Angeli, Milano, 1981.

MARLETTI, Carlo, «Il terrorismo moderno come strategia di comunicazione. Alcune considerazioni a partire dal caso italiano», en VILLA, Renzo, La violenza interpretata, Il Mulino, Bologna, 1979.

MASTROLILLI, Paolo y MOLINARI, Maurizio: L'Italia vista dalla Cia: 19482004, Laterza, Roma-Bari, 2005.

MASTROMATTEO, Gilberto, Quando i media staccano la spina, Prospettiva Editrice, Civitavecchia, 2007.

MORETTI, Mario, Brigate Rosse. Una storia italiana, Milano, Baldini\&Castoldi, 2002.

MORO, Aldo, Ultimi scritti, Piemme, Casale Monferrato, 2003.

MURIALDI, Paolo, «Caso Espresso e black out: un riepilogo», en Problemi dell'informazione, Il Mulino, Bologna, n. 1, 1981.

MURIALDI, Paolo, Storia del giornalismo italiano, Torino, Gutenberg 2000, 1986.

PACINI, Giacomo (2014): Le altre Gladio: la lotta segreta anticomunista in Italia, 1943-1991, Einaudi, Turín, 2014.

PROGETTO MEMORIA, Le parole scritte, Sensibili alle foglie, Roma, 1996.

RAYNER, Hervé: «Les théories du complot dans les interpretations du terrorisme en Italie: la prégnance du pont de vue cryptologique», en Giuseppe GARGIULO y Otmar SEUL: Terrorismes : l'Italie et l'Allemagne à l'épreuve des «années de plomb», 1970-1980, M. Houdiard, París, 2008.

RIVAS NIETO, Pedro, Terrorismo y antiterrorismo en el mundo contemporáneo, Debate, Madrid, 2013.

TRANFAGLIA, Nicola: «Un capitolo del 'doppio stato': la stagione delle stragi e dei terrorismi, 1969-84», en Francesco BARBAGALLO, coord., Storia dell'Italia repubblicana, Einaudi, Turín, III-2, 1997.

VERES, Luis, «Prensa, poder y terrorismo», Amnis. Revue de Civilisation Contemporaine Europe/Amerique de l'Université de Bretagne Occidentale [en ligne], n. 4, 2004, p. 1-9.

ZAVOLI, Sergio, La notte della repubblica, Mondadori, Milano, 1992.

\section{Financiación}

Este estudio forma parte del proyecto «El terrorismo europeo en los años de plomo: un análisis comparativos» (HAR2015-65048-P), financiado por el Plan Nacional I+D+I del Ministerio de Economía y Competitividad. 
Dejar de informar: la prensa italiana y el debate...

\section{Datos del autor}

Matteo Re (matteo.re@urjc.es), doctor en Historia Contemporánea y profesor en la Universidad Rey Juan Carlos de Madrid. Ha sido profesor en la UNED, en el Istituto Italiano di Cultura de Madrid y en la Escuela Diplomática. Profesor del Master universitario Análisis y prevención del terrorismo de la URJC.

Entre sus publicaciones: No quieren cambiar. Códigos, lenguaje e historia de la mafia. Dykinson, 2016; Guerrilleros, terroristas y revolución. Thomson Reuters-Aranzadi, 2015; Pertenencia a banda armada. Ataque al corazón del Estado y terrorismo en Italia. Biblioteca Nueva, 2013; "Spettrografia delle Brigate Rosse» en Nuova Storia Contemporanea, 2012; "Meccanismi di radicalizzazione política all'interno dei Tupamaros uruguaiani e dei Montoneros argentini: contatti, influenze e guerriglia urbana» en Nuova Rivista Storica, 2014; "Dalla guerriglia al governo democratico. Come i Tupamaros sono arrivati al potere» en Studi Storici, 2012; "Elementos identitarios de la violencia política internacional: análisis comparado de los Tupamaros y de las Brigadas Rojas" en Estudios Ibero-Americanos, 2012. Estas últimas publicaciones se han realizado junto con el profesor José Manuel Azcona. 